\title{
Electricity Pricing Mechanism of Industrial Users Based on Power Quality
}

\author{
Ke Wang \\ Department of Electrical Engineering, North China Electric Power University(Baoding), Baoding, \\ 071003,China
}

631401282@qq.com

Keywords: Power quality, Fuzzy clustering analysis, Industrial electricity price, Pricing method.

\begin{abstract}
Based on the premise that the power company's income is the same, the pricing model of industrial users' electricity price based on power quality is put forward according to the difference of power quality consumed by industrial users. The model uses fuzzy clustering analysis to evaluate the power quality and determine the power quality level of each user, and then determine the ladder pricing mechanism according to the evaluation results. This model is illustrated by industrial users in a region, and the effectiveness of the model is analyzed.
\end{abstract}

\section{Introduction}

With the continuous advancement of China's electric power system reform[1], the model of differential price is applied. The main purpose is to suppress the energy consumption and the heavy pollution of high energy consumption enterprises.

At present, the industrial user's electricity charge consists of tariff regulation by power factors . Tariff regulation by power factors is based on the level of user power factor level reduction or increase in electricity, taking into account the user's impact on the stable operation of the grid. But the electricity The demand for power quality varies from user to user. Some enterprises of the equipment on the power quality and reliability of power supply requirements are getting higher and higher. The impact of power quality problems in the production of enterprises is also growing. Obviously for all enterprises, regardless of the difference in power quality, the implementation of the same price is unreasonable.

In this paper, based on the premise that the power company's income is the same, the pricing model of industrial users based on power quality is put forward according to the difference of power quality of industrial users. The model first uses the fuzzy clustering analysis to evaluate the power quality and determine the power quality level of each user, and then determine the ladder pricing mechanism according to the evaluation results.

\section{Design of Industrial Electricity Price Model Based on Power Quality}

In order to ensure the user's demand for power quality, the power company needs to implement the differentiated electricity price according to the different power quality to guarantee the reasonable demand of the user.

Differentiated electricity prices generally include the base price and the fluctuation price. In general, the basic electricity price for the government documents provided by the Internet price; fluctuation price is based on different power quality level to determine. It can be designed as follows:

$$
p=p_{0}+\Delta p
$$

In the type, $p$ is the electricity price of per kWh of the industrial user; $p_{0}$ is the basic electricity price of per $\mathrm{kWh} ; \Delta p$ is the fluctuating electricity price of per $\mathrm{kWh}$. 
The fluctuating price depends on the quality of the power received by the user, but the return of the power supply company should be kept constant. The price of the fluctuation can be designed as follows:

$$
\Delta p=k \cdot m+p_{1}
$$

In the type, $k$ is the price gradient; $m$ is the weighting factor, depending on the power quality; $p_{1}$ is the fixed price of per kWh to ensure that the power supply company earnings unchanged.

The value of A is discussed next: Suppose there are five power quality levels, each power quality level corresponding to the weighting coefficient of $m_{1}, m_{2}, m_{3}, m_{4}, m_{5}$, the price gradient is $k$, the power consumption per level were : $W_{1}, W_{2}, W_{3}, W_{4}, W_{5}$. Without considering the fixed price , the electricity payable shall be:

$$
\begin{aligned}
C & =\left(p_{0}+m_{1} k\right) \cdot W_{1}+\left(p_{0}+m_{2} k\right) \cdot W_{2}+\left(p_{0}+m_{3} k\right) \cdot W_{3}+\left(p_{0}+m_{4} k\right) \cdot W_{4}+\left(p_{0}+m_{5} k\right) \cdot W_{5} \\
& =p_{0} \cdot \sum_{i=1}^{5} W_{i}+k \cdot \sum_{i=1}^{5} m_{i} W_{i}
\end{aligned}
$$

The original electricity charges that the power supply company should charge are as follows:

$$
C^{\prime}=p_{0} \cdot \sum_{i=1}^{5} W_{i}
$$

The difference between the two is:

$$
\Delta C=-k \cdot \sum_{i=1}^{5} m_{i} W_{i}
$$

As the gradient price is determined by the difference in power quality difference, then the gradient should be guaranteed price unchanged, then the fixed price is:

$$
p_{1}=\frac{\Delta C}{\sum_{i=1}^{5} W_{i}}
$$

Therefore, the price can be expressed as a unified:

$$
p=p_{0}+m \cdot k+p_{1}=p_{0}+m \cdot k+\frac{\left(-k \cdot \sum_{i=1}^{5} m_{i} W_{i}\right)_{i}}{\sum_{i=1}^{5} W_{i}}
$$

In the type: $i$ is the power quality level of the user

In this model, there are two parameters that need to be set up reasonably, one is the tariff gradient and the other is the weighting factor. As part of the volatility price, the gradient price is a fixed parameter, usually determined by the power company according to the survey, such as set to 1/5 of the base price. The weighting factor is a step-by-step system based on the quality of power that takes full account of the impact of different power quality on the user. We generally divided the power quality into five levels, one best, five worst. For example, Table 1 is a viable tariff weighting factor.

Tab.1 Weighting coefficients corresponding to different power quality

\begin{tabular}{|c|c|c|c|c|c|}
\hline Power Quality & 1 & 2 & 3 & 4 & 5 \\
\hline Weighting factor & $1 / 2$ & $1 / 3$ & 0 & $-1 / 3$ & -1 \\
\hline
\end{tabular}

\section{The Realization of Industrial Electricity Price Model Based on Power Quality}

\subsection{Design of Industrial Electricity Price Model}

Standards related to power quality are as follows: GB/T 12325 - 2008 Power quality-Deviation of supply voltage; GB 12326 - 2008 Power quality-Voltage fluctuation and flicker; GB/T 14549—1993

Quality of electric energy supply -Harmonics in public supply network; GB/T $15543-2008$ Power quality-Three-phase voltage unbalance; GB/T 15945 - 2008 Power quality-Frequency 
deviation for power system; GB/T 18481 - 2001 Power quality-Temporary and transient over voltages. These standards describe the indicators and influencing factors of grid power quality. Taking into account the actual situation of industrial users, combined with the impact of power quality indicators, select the Voltage deviation, Voltage fluctuations, Voltage flicker, Voltage total harmonic distortion $\left(T H D_{u}\right)$, Current total harmonic distortion $\left(T H D_{i}\right)$, Three-phase imbalance, Frequency deviation as seven indicators of industrial users to conduct a comprehensive assessment of power quality[2].

\subsection{Comprehensive Evaluation of Power Quality Based on Clustering Theory}

The mathematical method of sorting things according to certain requirements is clustering analysis, which belongs to a multivariate analysis of mathematical statistics. Because some of the indicators of power quality are ambiguous, the fuzzy mathematics language is used to deal with it. The use of clustering ideas to comprehensively evaluate the power quality can be roughly divided into four steps[3-4]:

Step 1: Standardize the data.

Step 2: Create a fuzzy similarity matrix.

Step 3: Fuzzy clustering.

Step 4: Determine the best clustering

\section{Examples of analysis}

The parameters of the power quality of four industrial users in a region $110 \mathrm{kV}$ power grid are shown in Table 2.

Tab.2 Power quality index information

\begin{tabular}{|c|c|c|c|c|c|c|c|}
\hline $\begin{array}{c}\text { User } \\
\text { number }\end{array}$ & $\begin{array}{c}\text { Voltage } \\
\text { deviation }\end{array}$ & $\begin{array}{c}\text { Voltage } \\
\text { fluctuations }\end{array}$ & $\begin{array}{c}\text { Voltage } \\
\text { flicker }\end{array}$ & $T H D_{u}$ & $T H D_{i}$ & $\begin{array}{c}\text { Three-phas } \\
\text { e imbalance }\end{array}$ & $\begin{array}{c}\text { Frequency } \\
\text { deviation }\end{array}$ \\
\hline 1 & 3.58 & 0.086 & 0.023 & 1.903 & 1.863 & 1.744 & 0.03 \\
\hline 2 & 8.72 & 0.085 & 0.017 & 2.091 & 2.128 & 2.348 & 0.03 \\
\hline 3 & 4.08 & 0.112 & 0.014 & 1.572 & 1.436 & 1.597 & 0.03 \\
\hline 4 & 7.72 & 0.096 & 0.020 & 2.169 & 2.067 & 2.722 & 0.03 \\
\hline
\end{tabular}

According to the national standard and refer to the boundaries of other literature[5]. This paper divides the power quality into five levels. The specific breakdown of each indicator is shown in Table 3.

Tab.3 Levels of different power quality indicators

\begin{tabular}{|c|c|c|c|c|c|c|c|}
\hline $\begin{array}{c}\text { Power } \\
\text { quality } \\
\text { rating }\end{array}$ & $\begin{array}{c}\text { Voltage } \\
\text { deviation } \\
/ \%\end{array}$ & $\begin{array}{c}\text { Voltage } \\
\text { fluctuations } \\
/ \%\end{array}$ & $\begin{array}{c}\text { Voltage } \\
\text { flicker } \\
/ p_{s t}\end{array}$ & $\begin{array}{c}T H D_{u} \\
/ \%\end{array}$ & $\begin{array}{c}T H D_{i} \\
/ \%\end{array}$ & $\begin{array}{c}\text { Three-phas } \\
\text { e imbalance } \\
/ \%\end{array}$ & $\begin{array}{c}\text { Frequency } \\
\text { deviation } \\
/ \mathrm{Hz}\end{array}$ \\
\hline Q1 & 2 & 0.1 & 0.05 & 0.4 & 0.4 & 0.4 & 0.04 \\
\hline Q2 & 4 & 0.2 & 0.10 & 1.2 & 1.2 & 1.2 & 0.12 \\
\hline Q3 & 6 & 0.3 & 0.15 & 1.8 & 1.8 & 1.8 & 0.18 \\
\hline Q4 & 8 & 0.4 & 0.20 & 3.6 & 3.6 & 3.6 & 0.36 \\
\hline Q5 & 10 & 0.5 & 0.25 & 5.2 & 5.2 & 5.2 & 0.52 \\
\hline
\end{tabular}

The clustering results are shown in Table 4:

Tab.4 Cluster results

\begin{tabular}{|c|c|c|}
\hline Threshold & Cluster results & Whether it is best \\
\hline 0.98866 & $\{\mathrm{Q} 1\}\{\mathrm{Q} 2\}\{\mathrm{Q} 3\}\{\mathrm{Q} 4\}\{\mathrm{Q} 5\}\{1,3\}\{2,4\}$ & $\mathrm{N}$ \\
\hline 0.9732 & $\{\mathrm{Q} 1\}\{\mathrm{Q} 2\}\{\mathrm{Q} 3\}\{\mathrm{Q} 4,1,3\}\{\mathrm{Q} 5\}\{2,4\}$ & $\mathrm{N}$ \\
\hline 0.9673 & $\{\mathrm{Q} 1\}\{\mathrm{Q} 2\}\{\mathrm{Q} 3,1,3\}\{\mathrm{Q} 4,2,4\}\{\mathrm{Q} 5\}$ & $\mathrm{Y}$ \\
\hline
\end{tabular}

The electricity consumption of each user is shown in Table 5: 
Tab.5 Power consumption of users

\begin{tabular}{|c|c|c|c|c|}
\hline User number & 1 & 2 & 3 & 4 \\
\hline Monthly electricity consumption/kWh & 18829 & 98764 & 43123 & 76321 \\
\hline
\end{tabular}

The electricity price of $110 \mathrm{kV}$ users in this area is $0.5711 / \mathrm{kWh}$. Assuming that the electricity price gradient is $1 / 3$ of the basic electricity price, then:

The electricity price of per kWh for users 1 and 2 is:

$$
p^{\prime}(1 、 3)=p_{0}+k \cdot m=0.5711 ¥ / \mathrm{kWh}
$$

The electricity price of per kWh for users 3 and 4 is:

$$
p^{\prime}(2 、 4)=p_{0}+k \cdot m=0.5711+(-1 / 3) \times 0.19=0.5076 ¥ / \mathrm{kWh}
$$

The fixed price:

Finally:

$$
P_{1}=\frac{\left(-k \cdot \sum_{i=1}^{5} m_{i} W_{i}\right)}{\sum_{i=1}^{5} W_{i}}=0.0469 ¥ / \mathrm{kWh}
$$

$$
\begin{aligned}
& p(1 、 3)=p_{0}+k \cdot m+p_{1}=0.5711+0.0469=0.6180 ¥ / \mathrm{kWh} \\
& p(2 、 4)=p_{0}+k \cdot m+p_{1}=0.5076+0.0469=0.5545 ¥ / \mathrm{kWh}
\end{aligned}
$$

\section{Conclusions}

In this paper, a comprehensive evaluation model of power quality of industrial users is designed based on the difference of power quality in the process of industrial users' electricity consumption. Based on this, a calculation model of electric power price of industrial users based on power quality is proposed. The results show that the model can reasonably evaluate the power quality of industrial users and differentiate the electrical price of users with different power quality. For the power supply, the electricity price of industrial users is verified by reference to the relevant literatures. Fairness of the promotion has a positive meaning. The model has a simple structure. For the future electricity market, industrial users can provide a practical scheme according to the electric power quality rating. The model has a certain reference value even if the future electricity market adopts different marketing strategies.

\section{References}

[1] Liu Qingwei, A Study of The Integration Model on The Tariff and Sales Price Under The Condition of Power Market[D], Chengdu: Xihua University . 2013.

[2] Sun Shiqiang, The Research of Power Quality Comprehensive Evaluation Method[D], Changsha, Hunan University, 2013.

[3] Jiang De-long, Wang Ke-wen, Yang Ping, Cui Wei, Power quality comprehensive evaluation based on the clustering method[J], Power System Protection and Control, 2012, 40(7): 105-111.

[4] Du Peiwei, Power Quality Evaluation Methods Based on Cluster Analysis[D], Changsha, Hunan University, 2013.

[5] ZHANG Yong-jun, CHEN Chao, XU Liang. Prediction of original reliability parameters of power system based on fuzzy clustering and similarity[J]. Power System Protection and Control, 2011, 39(8): 1-5. 